\title{
Decrease of soil adhesion to working bodies of earth-moving machines
}

\author{
S.A. Zenkov \\ Mechanical Faculty \\ Bratsk State University \\ Bratsk, Russia \\ mf@brstu.ru
}

\author{
N.A. Balahonov \\ Mechanical Faculty \\ Bratsk State University \\ Bratsk, Russia \\ balaxon-off@mail.ru
}

\author{
O.P. Kirichenko \\ Department of Foreign Languages \\ Bratsk State University \\ Bratsk, Russia \\ vladxpohoc@gmail.com
}

\begin{abstract}
When the moist soil is excavated, the soil sticking and freezing to the working units of the earth-moving machines take place. It is the phenomenon that considerably reduces the plant's efficiency. There are four main groups of methods intended for eliminating adhesion of soil to the surface of the working bodies of earth-moving machines. As for the nature and the operating effects of the methods, they can be divided into the preventive methods and the means ones for cleaning the working units of the earth-moving machines. On the special shear stand, the multifactorial test has been conducted using mathematical theory of experiment to determine the practical effect of antiicing liquid usage as a preventive method when the intermediate layer is used in the contact point "soil-to-working units" to reduce adhesion to metal surfaces soil machines. Mathematical processing of the obtained results was carried out using the MODEL program for multifactor dependencies using the least squares method. As a result of the processing of experimental data, regression equations were obtained without the action of the lubricant and with the use of anti-icing fluids "MAXFLIGHT 04" and "OCTAFLO EG". Multifactorial dependences of shear stress are obtained. To interpret the results obtained, quasi-onefactor dependences are given for fixed values of two factors among three, the response surfaces for quasi-one-factor dependencies for anti-icing fluids of the brands MAXFLIGTH 04 and OCTAFLO EG are constructed. Analysis of these dependencies in the investigated range of factor changes shows that the use of anti-icing fluids of the brands MAXFLIGTH 04 and OCTAFLO EG reduces the shear stress to $60 \%$.
\end{abstract}

Keywords - adhesion, anti-icing fluid, «MAXFLIGHT 04», «OCTAFLO EG», soil, shear stand.

\section{INTRODUCTION}

The main reason for the decline in the productivity of earthmoving machinery is the increase in adhesion and friction in the development of wet cohesive soils under conditions of negative temperatures. Adhesive phenomena cause a sharp increase in frictional forces, which constitute $30-60 \%$ of the pulling force [1-3].

The existing methods of reducing friction and adhesion can be divided into four groups. The first method involves the creation of an intermediate layer at the interface of the contact, which can serve as a protective screen for the molecular interaction of phases and must have an adhesive interaction. The second group includes methods that promote the weakening of adhesion bonds due to external influences. The third method is based on constructive-technological and mechanical methods. The fourth group is the combination of two or more methods to reduce adhesion [4,5].

A widely used and promising preventive method of combating adhesion is the creation of an intermediate layer at the contact boundary of the "working surface-soil" system. This layer plays the role of a screen to prevent the intermolecular interaction, i.e. provides freedom of relative displacement of phase surfaces and can be liquid, solid and gaseous. The thickness of the layer must be determined for its anti-adhesion properties [6-8].

\section{MATERIALS AND EQUIPMENT FOR RESEARCH}

Let's consider the effect of anti-icing liquid as the intermediate layer.

Anti-icing fluids "MAXFLIGHT 04" and "OCTAFLO EG" are de-icing fluids based on propylene glycol and are intended for ground anti-icing aircraft treating. The liquids have a very good anti-icing performance when used up to $+70^{\circ} \mathrm{C}$ without any operational restrictions. The anti-icing liquid must be retained on the wings (Holdvertime) for the time period from 3 minutes to 12 hours. The "MAXFLIGHT 04" anti-icing fluid has the highest safety margin of all available SAE type IV fluids between the viscosity value of the product on delivery and the lowest allowable viscosity value from the overall table, and maintains good aerodynamic 
performance of the aircraft. It has unique characteristics making it one of the most perfect liquids corresponding to SAE type IV, available on the market. It has the lowest viscosity limits of all SAE type IV fluids, in some cases even lower than for liquids corresponding to SAE type II. Provides the greatest safety margin between the lower viscosity value for production and the viscosity on the wing.

Liquid "OCTAFLO EG" is designed to remove snow, ice, frost and other kinds of ice formation from the surface of the aircraft, as well as to prevent icing of the aircraft after ice formation removal. The liquid "OCTAFLO EG" applied on the land at an outdoor temperature is not less than minus $44^{\circ}$ C. According to international standards, it belongs to the type I and complies with the requirements of ISO 11075, SAE / AMS 1424. As well as TU 6-00-5763445-10-89.

The experiments have been made to control the shift of the wet bonded earth against the metal surface using the anti-icing fluids "MAXFLIGHT 04" and "OCTAFLO EG", at air temperatures in the range from -35 to $+5{ }^{\circ} \mathrm{C}$. The experiments were made on a special shear stand $[9,10]$. 1.

The schematic diagram of the shear stand is shown in Fig.

The stand (fig. 1) consists of the frame 1 with screws 2, the bolted joints 3 guides 4 , the carriage 5 provided with rollers 6 and installed movably in guides 4, rigidly fixed on the carriage, the AIL tanks 7 (pro-vided with AIL feeding system 32), with the heat isolated case 8 and a metal shift surface 9, a cylindrical holder 10 without bottom, a removable ring 11, a stamp 12 and cap 13. The stamp 12 by the threaded coupling is connected with the bar 14 which can move vertically in a guide bush 15 and is hinged to the load lever 16 one end of which on was the support is 17 where replaceable loads 18 are located. The holder 10 held by studs 19 and nuts 20 is attached to a metal structure 1, and can be regulated and is provided with a heat-insulating housing 21 . The removable ring 11 is fixed in it by two bolts 22. The removable ring 11 is made of shock-resistant highpressure polyethylene. The inner diameter of the ring 11 is equal to the external diameter of a stamp 12. The stamp is hollow and has bores 23 and 24 to intake and outtake the coolant (50\% ethylene glycol solution) and has a tight cap 13 made of material having heat conductivity greater than that of stamp material 12 . The stamp cavity 12 is filled with coolant (50\% ethylene glycol solution), connected by the heatisolated pipe lines via the three-running cock 25 , a cooler 26 , the cock 27 to coolant reservoir 28 .

The carriage 5 with the tank, filled with anti-icing liquid 7 through the load cell (model ST) 29, is connected to the drive mechanism 30 consisting of a traction winch, a P-21 DC motor (powered from the mains via a RNO-250-2 transformer and a power diodes rectifier VL-200), worm-gear reducer PCh-3, V-belt drive, cam clutch located on the winch shaft.

The stand is equipped with a set of strain gauges 31 (an electronic dynamometer DOR-3-5I) and a device for measuring temperature and humidity 33 (with the moisture meter CENTER 315).

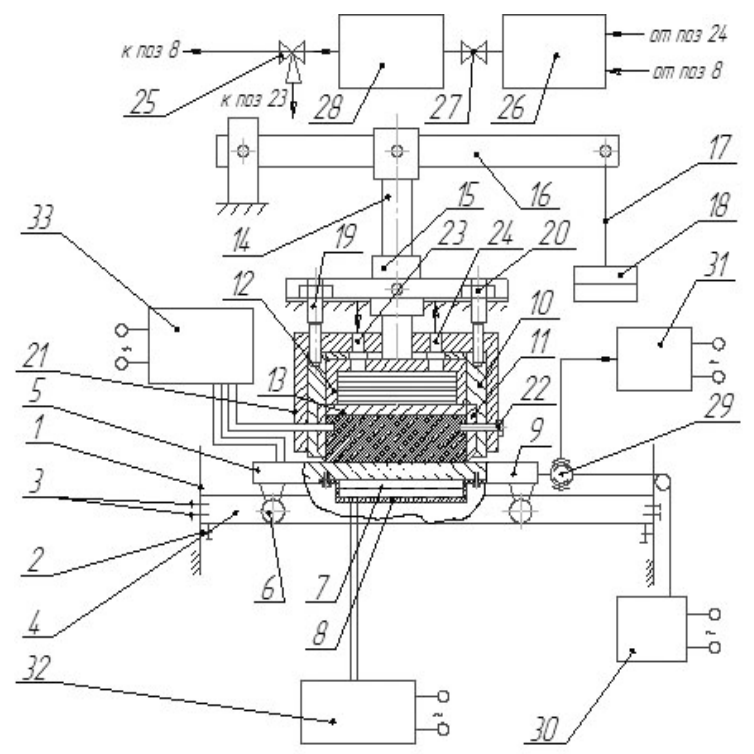

Fig. 1. Schematic diagram of the experimental shear stand for studying the effect of the liquid interlayer strength of soil freezing.

\section{THE RESULTS OF THE EXPERIMENT}

For experiments, soil was used - loam, with moisture values from 7.5 to $17.5 \%$, the time of contact of soil with metal from 3 to 7 minutes, corresponds to the working parameters of earth-moving machines. The plan and results of the experiments are given in Table 1.

TABLE I. THE PLAN AND RESULTS OF THE EXPERIMENT

\begin{tabular}{|c|c|c|}
\hline \multicolumn{3}{|c|}{ The experimental plan in natural values } \\
\hline $\begin{array}{c}\text { Ambient } \\
\text { temperature } \\
\text { Tat, }{ }^{\circ} \mathrm{C}\end{array}$ & $\begin{array}{c}\text { Soil moisture } \\
\mathrm{W}, \%\end{array}$ & $\begin{array}{l}\text { The contact } \\
\text { time of the } \\
\text { soil-metal } \\
\text { system } t \text {, min. }\end{array}$ \\
\hline 1 & 2 & 3 \\
\hline \multirow{5}{*}{-35} & 7.5 & 3 \\
\hline & 7.5 & 7 \\
\hline & 12,5 & 5 \\
\hline & 17,5 & 3 \\
\hline & 17,5 & 7 \\
\hline \multirow{5}{*}{-15} & 7,5 & 5 \\
\hline & 12,5 & 3 \\
\hline & 12,5 & 5 \\
\hline & 12,5 & 7 \\
\hline & 17,5 & 5 \\
\hline \multirow{5}{*}{+5} & 7.5 & 3 \\
\hline & 7.5 & 7 \\
\hline & 12,5 & 5 \\
\hline & 17,5 & 3 \\
\hline & 17,5 & 7 \\
\hline
\end{tabular}


TABLE II. RESULTS OF SHEAR FORCE MEASUREMENTS

\begin{tabular}{|c|c|c|}
\hline \multicolumn{3}{|c|}{ Results of shear force measurements, N } \\
\hline $\begin{array}{c}\text { Without } \\
\text { impact }\end{array}$ & $\begin{array}{c}\text { MAXFLIGHT } \\
\mathbf{0 4}\end{array}$ & $\begin{array}{c}\text { OCTAFLO } \\
\text { EG }\end{array}$ \\
\hline 4 & 5 & 6 \\
\hline 92.73 & 30.4 & 32.1 \\
\hline 174.2 & 62.74 & 65.3 \\
\hline 186.54 & 78.91 & 80.76 \\
\hline 218.54 & 134.2 & 136.9 \\
\hline 400 & 159.89 & 162.43 \\
\hline 63.74 & 38.25 & 40.3 \\
\hline 78.45 & 50.01 & 51.9 \\
\hline 144.2 & 56.88 & 58.12 \\
\hline 240.3 & 58.84 & 61.4 \\
\hline 228.5 & 94.14 & 96.6 \\
\hline 11.6 & 4.2 & 5.8 \\
\hline 15.2 & 5.1 & 6.57 \\
\hline 17.9 & 8.3 & 9.64 \\
\hline 24.3 & 14.8 & 16.1 \\
\hline 31.7 & 17.4 & 18.97 \\
\hline & & \\
\hline
\end{tabular}

Mathematical processing of the obtained results was carried out using the MODEL program for multifactor dependencies using the least squares method. As a result of the processing of the experimental data, regression equations were obtained without the action of the lubricant and with the use of anti-icing fluids "MAXFLIGHT 04" and "OCTAFLO EG".

Without impact:

$$
Y_{5 B}=134.3+1.026 \cdot T_{c p}-4.3 \cdot W-46.08 \cdot t-0.1 \cdot T_{c p}{ }^{2}+
$$

$0.1074 \cdot W^{2}+3.985 \cdot t^{2}-0.4 \cdot T_{c p} \cdot W-0.8 \cdot T_{c p} \cdot t+1.3 \cdot W \cdot t$

\section{«MAXFLIGHT 04»:}

$Y_{\text {Maxflight }}=41.22+0.66 \cdot T_{c p}-8.14 \cdot W+4.4 \cdot t-0.03 \cdot T_{c p}{ }^{2}+$ $0.43 \cdot W^{2}-0.27 \cdot t^{2}-0.22 \cdot T_{c p} \cdot W-0.17 \cdot T_{c p} \cdot t-0.062 \cdot W \cdot t$

\section{«OCTAFLO EG»:}

$$
Y_{\text {Octaflo }}=45.03+0.64 \cdot T_{c p}-8.4 \cdot \mathrm{W}+3.93 \cdot t-0.03 \cdot T_{c p}{ }^{2}+
$$

$0.44 \cdot W^{2}-0.21 \cdot t^{2}-0.224 \cdot T_{c p} \cdot W-0.172 \cdot T_{c p} \cdot t-0.07 \cdot W \cdot t$

Since the equations are multifactorial (which can not be displayed on an ordinary planar graph), it is necessary to build on them based quasi-one-factor relationships for fixed values of two factors of three.

The resulting single-factor equations are presented in Tables 2 and 3 .
TABLE III. SINGLE-FACTORY EQUATIONS OF SHEAR STRESS WITHOUT APPLICATION OF ANTI-ICING FLUID

\begin{tabular}{|c|c|c|c|c|}
\hline \multicolumn{9}{|c|}{ Without impact } \\
\hline № & $\begin{array}{c}\text { The natural values } \\
\text { of factors }\end{array}$ & Single-factor equations \\
\hline & $\begin{array}{c}\text { Tat, } \\
{ }^{\circ} \mathbf{C}\end{array}$ & $\mathbf{W , \%}$ & $\begin{array}{c}\mathbf{t}, \\
\text { min }\end{array}$ & \\
\hline \multicolumn{7}{|c|}{ Shear stress, N } \\
\hline 1 & 2 & 3 & 4 & 5 \\
\hline 1 & - & 17.5 & 7 & $Y=123.9-11.6 \cdot T_{c p}-0.1 \cdot T_{c p}{ }^{2}$ \\
\hline & - & 12.5 & 5 & $Y=47.81-7.974 \cdot T_{c p}-0.1 \cdot T_{c p}{ }^{2}$ \\
\hline & - & 7.5 & 3 & $Y=34.97-4.374 \cdot T_{c p}-0.1 \cdot T_{c p}{ }^{2}$ \\
\hline 2 & 5 & - & 7 & $Y=-18.365+2.8 \cdot W+0.1074 \cdot W{ }^{2}$ \\
\hline & -15 & - & 5 & $Y=25.635+8.2 \cdot W+0.1074 \cdot W^{2}$ \\
\hline & -35 & - & 3 & $Y=-42.485+13.6 \cdot W+0.1074 \cdot W{ }^{2}$ \\
\hline 3 & 5 & 17.5 & - & $Y=59.57-27.33 \cdot t+3.985 \cdot t^{2}$ \\
\hline & -15 & 12.5 & - & $Y=134.4-17.83 \cdot t+3.985 \cdot t^{2}$ \\
\hline & -35 & 7.5 & - & $Y=54.7-8.33 \cdot t+3.985 \cdot t^{2}$ \\
\hline
\end{tabular}

TABLE IV. SINGLE-FACTOR EQUATIONS OF SHEAR STRESS USING ANTI-

\begin{tabular}{|c|c|c|c|c|}
\hline \multicolumn{5}{|c|}{ With the use of anti-icing fluids } \\
\hline \multirow[t]{2}{*}{ № } & \multicolumn{3}{|c|}{$\begin{array}{c}\text { The natural values } \\
\text { of factors }\end{array}$} & \multirow{2}{*}{$\begin{array}{c}\text { Single-factor equations } \\
\text { «MAXFLIGHT 04» }\end{array}$} \\
\hline & $\begin{array}{l}\text { Tat, } \\
{ }^{\circ} \mathrm{C}\end{array}$ & $\begin{array}{l}\mathrm{W} \\
\%\end{array}$ & t, & \\
\hline \multicolumn{5}{|r|}{ Shear stress, $\mathbf{N}$} \\
\hline 1 & 2 & 3 & 4 & 5 \\
\hline \multirow[t]{3}{*}{1} & - & 17.5 & 7 & $Y=40.43-4.4 \cdot T_{c p}-0.03 \cdot T_{c p}^{2}$ \\
\hline & - & 12.5 & 5 & $Y=18-2.94 \cdot T_{c p}-0.03 \cdot T_{c p}^{2}$ \\
\hline & - & 7.5 & 3 & $Y=13.7-1.5 \cdot T_{c p}-0.03 \cdot T_{c p}^{2}$ \\
\hline \multirow[t]{3}{*}{2} & 5 & - & 7 & $Y=55.39-9.7 \cdot W+0.43 \cdot W^{2}$ \\
\hline & -15 & - & 5 & $Y=52.57-5.15 \cdot W+0.43 \cdot W^{2}$ \\
\hline & -35 & - & 3 & $Y=9.99-0.626 \cdot W+0.43 \cdot W^{2}$ \\
\hline \multirow[t]{3}{*}{3} & 5 & 17.5 & - & $Y=13.8+2.465 \cdot t-0.27 \cdot t^{2}$ \\
\hline & -15 & 12.5 & - & $Y=31.26+6.2 \cdot t-0.27 \cdot t^{2}$ \\
\hline & -35 & 7.5 & - & $Y=2.26+9.9 \cdot t-0.27 \cdot t^{2}$ \\
\hline \multirow[t]{2}{*}{1} & 2 & 3 & 4 & 5 \\
\hline & & & & «OCTAFLO EG» \\
\hline \multirow[t]{3}{*}{1} & - & 17.5 & 7 & $Y=41.425-4.484 \cdot T_{c p}-0.03 \cdot T_{c p}{ }^{2}$ \\
\hline & - & 12.5 & 5 & $Y=18.805-3.02 \cdot T_{c p}-0.03 \cdot T_{c p}^{2}$ \\
\hline & - & 7.5 & 3 & $Y=15.105-1.556 \cdot T_{c p}-0.03 \cdot T_{c p}^{2}$ \\
\hline \multirow[t]{3}{*}{2} & 5 & - & 7 & $Y=58.68-10.01 \cdot W+0.44 \cdot W^{2}$ \\
\hline & -15 & - & 5 & $Y=55.98-5.39 \cdot W+0.44 \cdot W^{2}$ \\
\hline & -35 & - & 3 & $Y=13.84-0.77 \cdot W+0.44 \cdot W^{2}$ \\
\hline \multirow[t]{3}{*}{3} & 5 & 17.5 & - & $Y=15.63+1.845 \cdot t-0.21 \cdot t^{2}$ \\
\hline & -15 & 12.5 & - & $Y=34.43 .+5.635 \cdot t-0.21 \cdot t^{2}$ \\
\hline & -35 & 7.5 & - & $Y=6.43+9.425 \cdot t-0.21 \cdot t^{2}$ \\
\hline
\end{tabular}
ICING FLUIDS 
a)

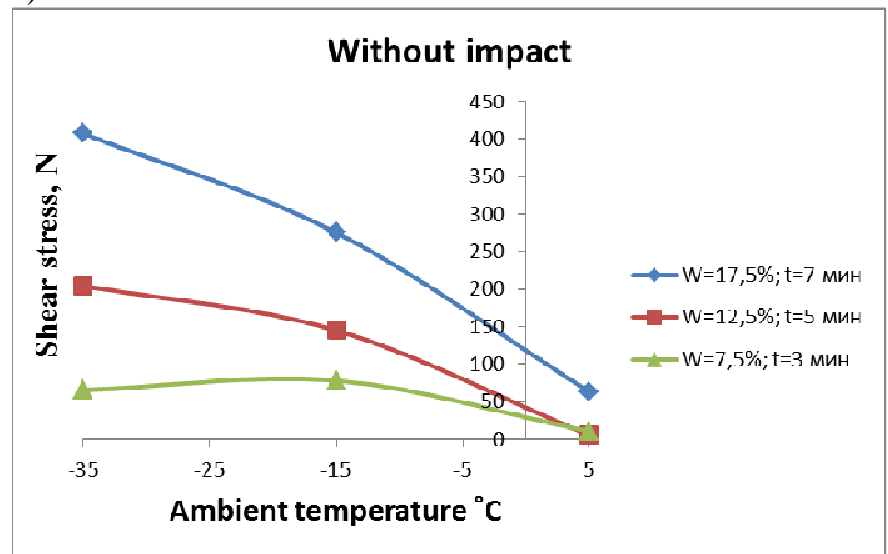

b)

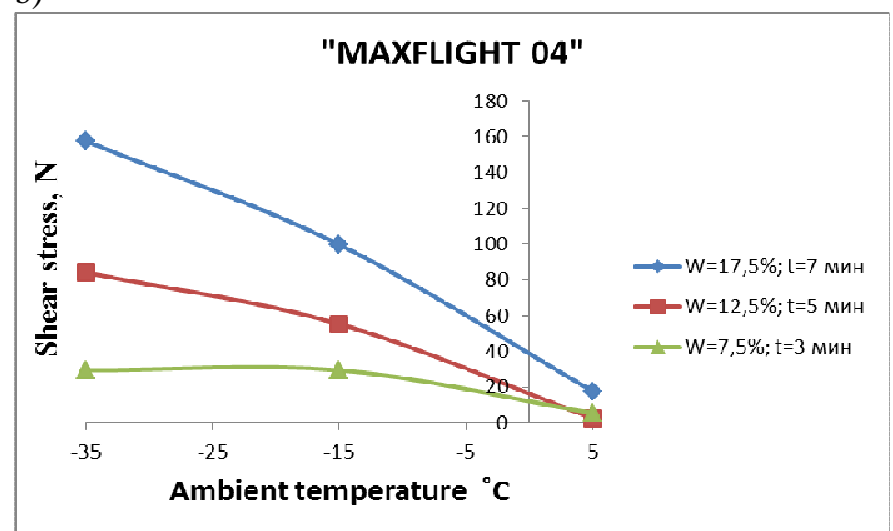

c)

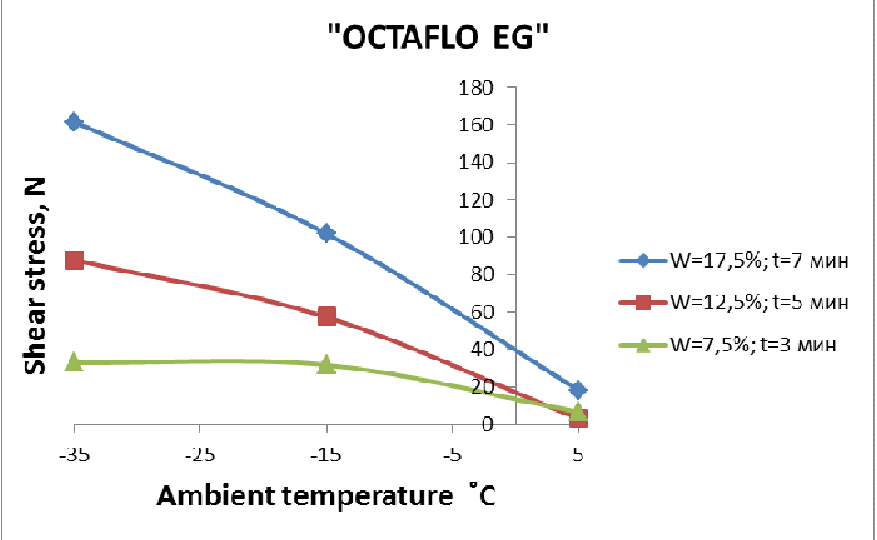

Fig. 2. Dependences of the shear stress on the ambient temperature in natural values: a) without impact the contact zone; b) using the MAXFLIGHT 04; c) Using the OCTAFLO EG.

Analysis of these dependencies in the investigated range of factor changes shows that as the ambient temperature decreases, the shear stress increases both with and without the action of the anti-icing fluid. With the application of the antiicing fluid "MAXFLIGHT 04", the shear stress decreases: for soil moisture $\mathrm{W}=17.5 \%$ and contact time $\mathrm{t}=7 \mathrm{~min}$, the shear stress is reduced by 55\%; at a soil moisture content of $\mathrm{W}=$ $12.5 \%$ and a contact time $\mathrm{t}=5 \mathrm{~min}$, the shear stress is reduced by $59 \%$; With a soil moisture content of $\mathrm{W}=7.5 \%$ and a contact time of $\mathrm{t}=3 \mathrm{~min}$, the shear stress is reduced by $51 \%$.
With the application of the anti-icing fluid "OCTAFLO EG", the shear stress decreases: it soil moisture is $\mathrm{W}=17.5 \%$ and contact time $\mathrm{t}=7 \mathrm{~min}$, the shear stress decreases by $53 \%$; it soil moisture is $\mathrm{W}=12.5 \%$ and contact time $\mathrm{t}=5 \mathrm{~min}$, the shear stress decreases by $57 \%$; it soil moisture is $\mathrm{W}=7.5 \%$ and contact time $\mathrm{t}=3 \mathrm{~min}$, the shear stress is reduced by $49 \%$.

a)

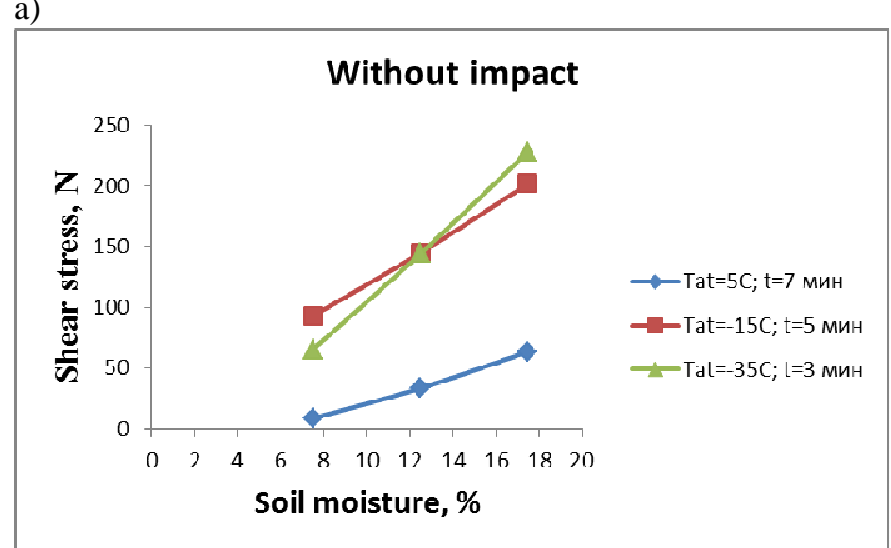

b)

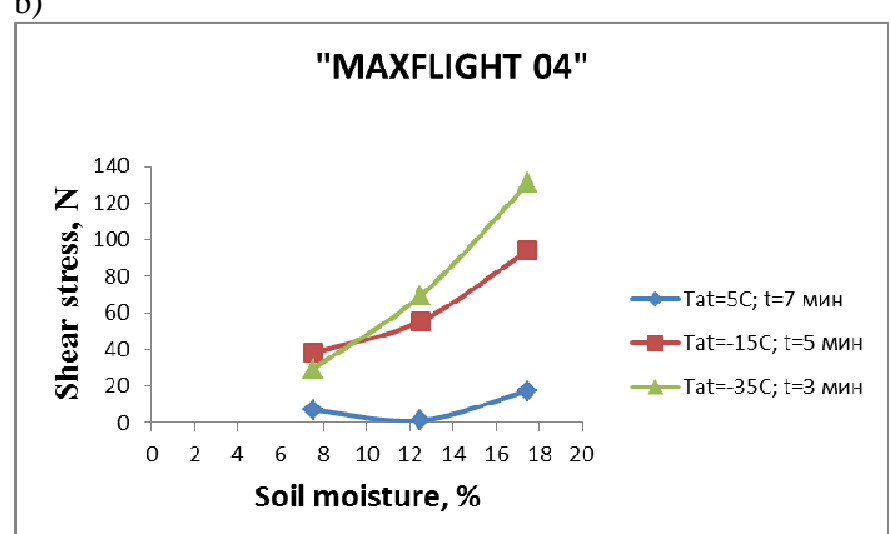

c)

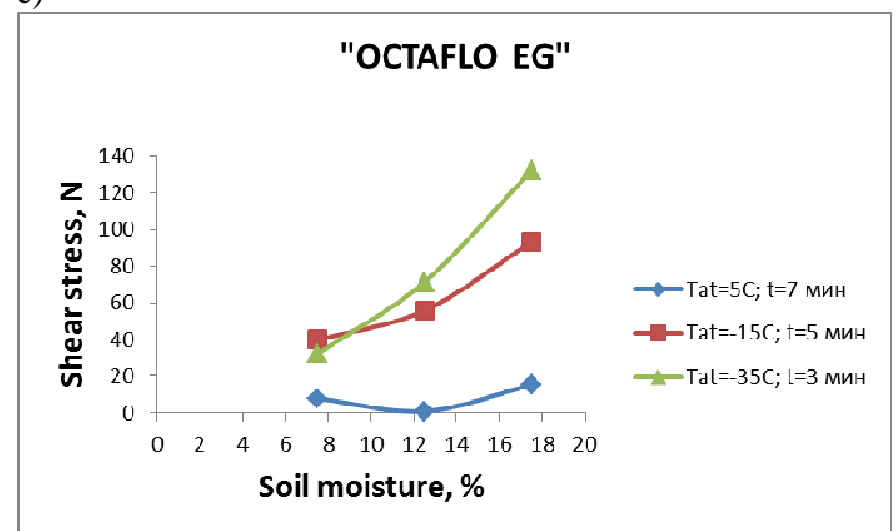

Fig. 3. Dependences of the shear stress on the soil moisture content in natural values: a) Without impact the contact zone; b) Using the MAXFLIGHT 04; c) Using the OCTAFLO EG.

Analysis of these dependences shows that as the moisture content of the soil increases, the shear stress increases. With the application of the anti-icing fluid "MAXFLIGHT 04", the shear stress decreases: at an ambient temperature of Tat $=5^{\circ} \mathrm{C}$ and a contact time of $\mathrm{t}=7 \mathrm{~min}$, the shear stress decreases by 
$43 \%$; at an ambient temperature of Tat $=-15^{\circ} \mathrm{C}$ and a contact time $\mathrm{t}=5 \mathrm{~min}$, the shear stress is reduced by $48 \%$; at an ambient temperature of Tat $=-35^{\circ} \mathrm{C}$ and a contact time of $\mathrm{t}=3 \mathrm{~min}$, the shear stress is reduced by $45 \%$. With the use of anti-icing fluid "OCTAFLO EG", the shear stress decreases: at ambient temperature Tat $=5^{\circ} \mathrm{C}$ and contact time $\mathrm{t}=7 \mathrm{~min}$, the shear stress decreases by $41 \%$; at an ambient temperature of Tat $=-15^{\circ} \mathrm{C}$ and a contact time $\mathrm{t}=5 \mathrm{~min}$, the shear stress decreases by $46 \%$; at an ambient temperature of Tat $=-35^{\circ} \mathrm{C}$ and a contact time $\mathrm{t}=3 \mathrm{~min}$, the shear stress is reduced by $43 \%$

a)

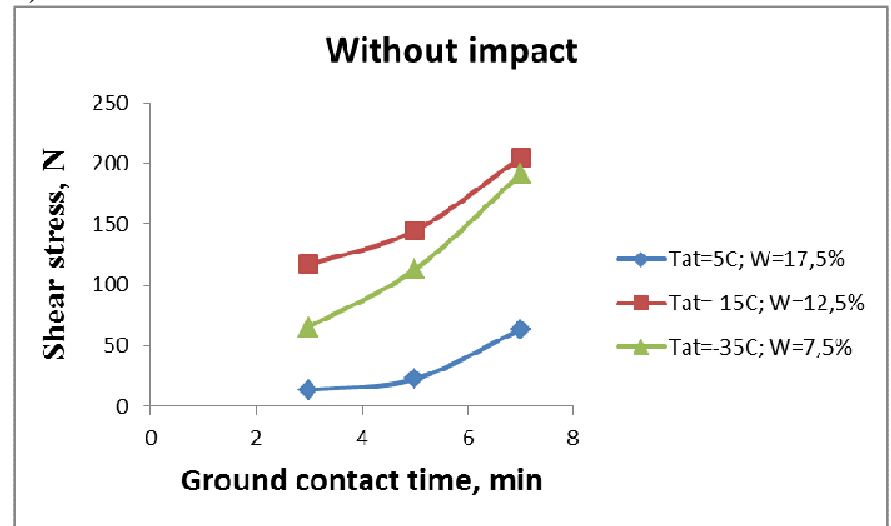

b)

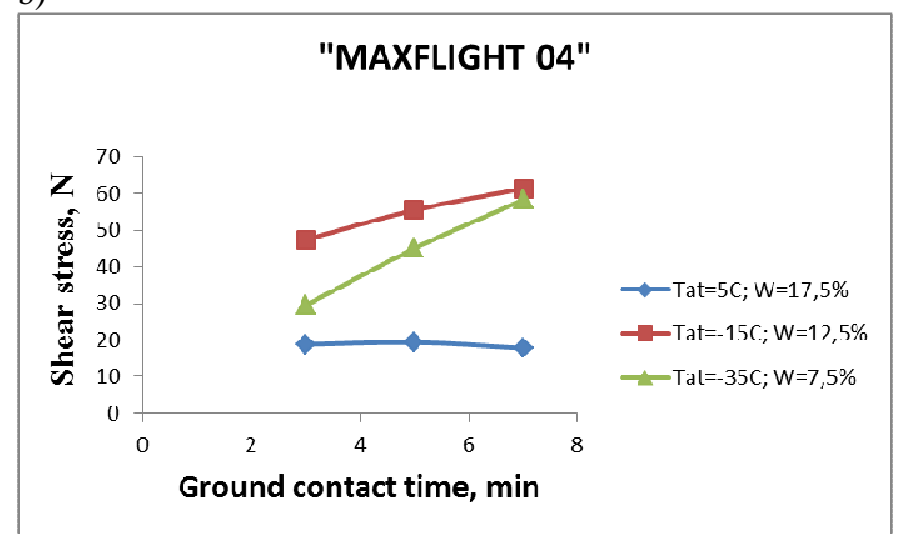

c)

\section{"OCTAFLO EG"}

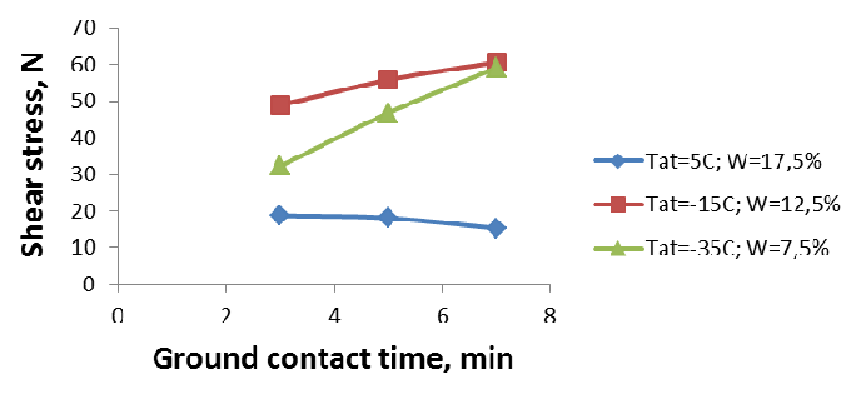

Fig. 4. Dependences of the shear stress on the contact time of the soil in natural values: a) Without impact the contact zone; b) Using the MAXFLIGHT 04; c) Using the OCTAFLO EG.
Analysis of these dependences shows that with increasing ground contact time with the metal surface, the shear stress increases. With application of anti-icing fluid "MAXFLIGHT 04", the shear stress decreases: at ambient temperature Tat $=5^{\circ} \mathrm{C}$ and soil moisture $\mathrm{W}=17.5 \%$, the shear stress decreases by 28\%; at an ambient temperature of Tat $=-15^{\circ} \mathrm{C}$ and a soil moisture content of $\mathrm{W}=12.5 \%$, the shear stress decreases by $36 \%$; at an ambient temperature of Tat $=-35^{\circ} \mathrm{C}$ and a soil moisture content of $\mathrm{W}=7.5 \%$, the shear stress is reduced by $32 \%$. With application of anti-icing fluid "OCTAFLO EG", the shear stress decreases: at ambient temperature Tat $=5^{\circ} \mathrm{C}$ and soil moisture $\mathrm{W}=17.5 \%$, the shear stress decreases by $26 \%$; at an ambient temperature of Tat $=$ $15^{\circ} \mathrm{C}$ and a soil moisture content of $\mathrm{W}=12.5 \%$, the shear stress is reduced by 34\%; at an ambient temperature of Tat $=-35^{\circ} \mathrm{C}$ and a soil moisture content of $\mathrm{W}=7.5 \%$, the shear stress is reduced by $30 \%$.

\section{CONCLUSION}

The results of the experimental studies of the effect of preventive action on the adhesion of soils to the metallic surface at a negative temperature make it possible to formulate a number of conclusions and practical recommendations. Sticking and soil freezing to the working bodies of excavating machines under negative temperatures. The most effective anti-icing liquid (of the brand) "MAXFLIGHT 04".

Under negative temperature of $-35^{\circ} \mathrm{C}$ using the anti-icing fluid "MAXFLIGHT 04", the shear stress of the "soil-metal" system is reduced by $50-60 \%$; at a negative temperature of $-15^{\circ} \mathrm{C}$, the shear stress decreases by $4-48 \%$; at a positive temperature of $5^{\circ} \mathrm{C}$, the shear stress decreases by $52-58 \%$.

The implementation of the above-mentioned methods and design solutions allow one to ensure an efficiency increase of earthmoving machinery that processes a moist soil under negative temperatures conditions.

\section{References}

[1] J. Tong, "Study on reducing adhesion and resistance of soil to soil engaging components of machinery for land locomotion by bionics". A Ph.D. Dissertation, Jilin University of Technology, Changchun, China (in Chinese), 1993.

[2] G. Rajaram, D. C. Erbach, "Journal of Terramechanics" vol. 36, pp. 3949, 1999.

[3] V. K. Sharma, L. O. Drew, L. Nelson, "Transactions of the ASAE", vol. 20, pp. 46-51, 1977.

[4] R. P. Zadneprovsky, Working bodies earthwork and reclamation machines and equipment for soil and high humidity materials, vol. 176 . Moscow: Mashinostroenie, 1992.

[5] N. A. Balahonov, D. A. Mineev, "The effect of repair and recovery compounds on the reduction of adhesion of soils to the working parts of machines", Nature, society, technology and thinking: trends and priorities. Collection of scientific papers on the materials of the I International Scientific and Practical Forum of Young Scientists, Russia, pp. 336-345, 2017.

[6] X. L. Wang, N. Ito, K. Kito, P. P. Garcia, "J. of Terramech", vol. 35, pp. 87-101, 1998. 
[7] G. Rajaram, D.C. Erbach, "Effect of wetting and drying on soil physical", Int. Agricultural Eng. vol. J.8, pp. 1-22, 1999.

[8] I. Buturovich, Han Duc Kim, "Calculation curved concentrators Trudy LPI", vol. 309, p. 169, 1969.

[9] S. Zenkov, E. Kurmashev, A. Elokhin, O. Krasavin, "Reducing soil adhesion forces on working bodies of road-construction machinery using piezoelectric ceramic actuators (transducers)", STU, Russia, vol. 1, pp. 346-351, 2009 [Digests 6th Scientific Conference "Polytransport systems in Siberia", 2009].

[10] S. A. Zenkov, N. A. Balahonov, K. A. Ignatev, "Analysis of the possible increase in excavator performance when removing soil adhesion to the bucket", Newsletter MGSU, Russia, vol. 2, pp. 98-104, 2014. 